\title{
Cambio de estilo y proyección de estatus: tratamientos en la correspondencia cortesana de principios del s. XVI*
}

\section{Change of Style and Demonstration of Status: Forms of Address in Courtly Correspondence in the Beginning of the 16 th Century}

\author{
Miguel Calderón Campos \\ Departamento de Lengua Española \\ Facultad de Filosofía y Letras \\ Universidad de Granada \\ Campus de Cartuja. Granada, 18071 \\ calderon@ugr.es \\ Orcid ID 0000-0002-0656-3643
}

RECIBIDO: 12 DE MARZO DE 2020 ACEPTADO: 25 DE MAYO DE 2020
Resumen: El presente artículo analiza el estilo personal del conde de Tendilla, capitán general del reino de Granada, en su último epistolario (15131515). En concreto, se centra en el análisis de los cambios de tratamiento en función de la imagen que el conde quiere proyectar de sí mismo y de los efectos que pretende provocar en el destinatario. Las cartas revelan dos esquemas básicos de trato: 1) voseo etimológico; 2) tratamientos indirectos (vuestra merced, vuestra señoría, vuestra alteza) con concordancia semántica o sintáctica, en función de la valoración social y del tono afectivo de la carta. El estudio muestra un variadísimo repertorio de estrategias gramaticales y discursivas, como el carácter directo de vos, que permite acortar la distancia entre los interlocutores, el recurso al vocativo señor como mecanismo de deferencia y atenuación, y el empleo de las fórmulas indirectas para reconocer el estatus nobiliario del interlocutor.

Palabras clave: Fórmulas de tratamiento. Estilo cortesano. Tratamientos indirectos. Siglo Xvı. Variación estilística.
Abstract: This paper analyses the personal style of the Count of Tendilla, captain-general of the kingdom of Granada, in his last collection of letters (15131515). Specifically, the study focuses on an analysis of the changes in forms of address, depending on the image the Count wished to project of himself and the effect he wished to have on the recipient. The letters show two basic patterns in the forms of address: 1) etymological voseo -or use of "vos" as a second person singular pronoun; and 2) indirect forms of address (vuestra merced, vuestra señoría, vuestra alteza) in semantic and syntactic concordance, depending on the social value and emotional tone of the letter. The study unveils a widely varied repertory of grammatical and discourse strategies, such as the direct nature of vos, which makes it possible to bridge the gap between the interlocutors, the use of the vocative señor as a means of deference and attenuation, along with the use of indirect forms of address to acknowledge the noble status of the interlocutor.

Keywords: Forms of Address. Courtly Style. Indirect Forms of Address. 16th Century. Stylistic Variation.

* Este trabajo se inscribe en el proyecto "Hispanae Testium Depositiones": las declaraciones de testigo en la bistoria de la lengua española. 1492-1833 (HISPATESD, FFI2017-83400-P, MINECO/AEI/FEDER/UE). 


\section{INTRODUCCIÓN}

- n este trabajo se analiza el complejo sistema de tratamiento que empleaba el conde de Tendilla en las cartas que escribió en los años finales de su vida (1513-1515). El epistolario (desde ahora Ep.Tendilla), publicado por Moreno Trujillo, de la Obra Sierra y Osorio Pérez (2007), consta de 1672 cartas (unas 420000 palabras), la mayoría dictadas por el conde a sus secretarios, otras escritas de su propia mano (Moreno Trujillo 41). Las últimas misivas (desde la número 1315) las redactó Luis Hurtado de Mendoza, hijo del conde y su sucesor tras su muerte en julio de 1515.

Íñigo López de Mendoza (c. 1442-1515), segundo conde de Tendilla, fue capitán general del reino de Granada y alcaide de la Alhambra desde 1492. Pertenecía al linaje de los Mendoza, una de las familias más influyentes y cercanas a los reyes Trastámara. Era nieto del marqués de Santillana y sobrino de Pedro González de Mendoza, el "Gran Cardenal”. Durante su gobierno tuvo que hacer frente a la revuelta de los mudéjares en el Albaicín (1499), lo que provocó el decreto de conversión forzosa de todos los musulmanes del reino. Desde la muerte de la reina Isabel (1504), una de las preocupaciones constantes de Tendilla, que se reflejan en el epistolario, fue la de conseguir y mantener el favor del rey Fernando y asegurar el relevo de poder en la figura de su hijo Luis.

Las cartas tienen un enorme valor para reconstruir la vida política, social y militar del reino de Granada en sus primeros años de incorporación a la Corona de Castilla: el conde se dirige a multitud de destinatarios de distinta posición social, desde el rey hasta capitanes del ejército, pasando por destacados miembros de la corte, obispos, arzobispos, corregidores, alcaides, miembros de los concejos ciudadanos, artesanos, etc. Con ellos trata de los temas más diversos, desde los más graves (asuntos de gobierno, de abastecimiento y disposición de las tropas ante la amenaza musulmana interna y del norte de África, intrigas cortesanas, nombramientos), hasta los más frívolos y cotidianos (aficiones, especialmente la caza, cotilleos, casamientos, achaques de su avanzada edad). La diversidad temática, de personajes y de actitud hacia ellos hacen del epistolario una fuente de enorme valor para analizar cómo D. Íñigo modificaba los esquemas de trato en función de sus intereses personales y políticos.

\section{MARCO TEÓRICO: CAMBIO DE ESTILO Y SOCIOLINGÜÍSTICA HISTÓRICA}

La moderna historia de la lengua, especialmente en sus enfoques sociolingüístico y pragmático, se ha caracterizado por la búsqueda afanosa de documentación no literaria lo más cercana posible a la oralidad: desde los años 90 se vie- 
nen elaborando corpus documentales, primero en papel y poco después en formato digital, donde tienen cabida nuevos géneros textuales: inventarios de bienes (Morala; Torres Martínez 2014; Morala/Egido Fernández; Puche Lorenzo; Bastardín Candón; Arrabal Rodríguez), declaraciones de testigos en juicios criminales (Calderón Campos 2019a), autobiografías (Rivadeneira, en este volumen) y diarios de soldados, relaciones geográficas (Bravo-García), quejas (Toledo y Huerta/Pons Rodríguez), notas de entrega de niños expósitos (Sánchez-Prieto Borja/Vázquez Balonga; Torres Martínez 2019), etc. Entre ellos, las cartas personales (Vaamonde 2018a; 2018b) destacan por su proximidad a lo oral, especialmente si están escritas por semicultos, suponen implicación emocional, se dirigen a familiares o amigos íntimos y presentan cierto grado de dialogicidad (Arias Álvarez/Hernández Mendoza 10-11). Todos estos rasgos, a excepción del primero, están presentes en el Ep.Tendilla, como podrá comprobarse en los apartados que siguen.

Estas características del género epistolar lo hacen especialmente adecuado para el estudio de la evolución de las fórmulas de tratamiento, con enfoques clásicos de sociolingüística o pragmática históricas (Fontanella de Weinberg; García-Mouton; Bentivoglio; Medina Morales; Stangl). Menos explorado está en español el llamado enfoque constructivista (Hernández-Campoy/Cutillas-Espinosa 2012), recientemente utilizado para estudiar el cambio de estilo en el discurso político, en la interacción en los medios y en el género epistolar.

En este modelo, la variación estilística no se contempla meramente como un fenómeno pasivo y automático (reactivo), condicionado por aspectos externos como la audiencia o la formalidad de la situación, sino como un fenómeno creativo, moldeable y estratégico (proactivo), en el que el propio hablante toma decisiones estilísticas para proyectar una imagen de sí mismo adecuada a sus fines comunicativos. Es lo que se desprende, por ejemplo, del comportamiento lingüístico de unos políticos murcianos, que exageraron a propósito el acento vernáculo para destacar su identidad local y sus ideas socialistas (Hernández-Campoy/Cutillas-Espinosa 2010).

Este enfoque, centrado en el estudio del comportamiento de hablantes particulares, se aplica provechosamente al estudio de corpus históricos de correspondencia (Nurmi/Nevala/Palander-Collin; Dossena/Del Lungo Camiciotti; Auer; Conde-Silvestre; Hernández-Campoy/García-Vidal 2018a; Eckert), puesto que la variación estilística de un informante concreto ("intra-speaker variation”) complementa la comprensión del funcionamiento de las prácticas so- 
ciolingüísticas de una determinada comunidad de habla, y de manera especial, permite detectar las variables lingüísticas más destacadas para la proyección de la propia identidad (Bell; Coupland). Este es el caso, por ejemplo, del comportamiento de sir John Paston II (1442-1479) en unas cartas dirigidas al rey, en las que, en contra de lo esperado, emplea una variante ortográfica especialmente identificada con el vernáculo y el mundo rural, en lugar de la forma innovadora más prestigiosa, probablemente como estrategia para mostrarse más "auténtico", más cercano y afectuoso y conseguir el favor real (Hernández-Campoy/García-Vidal 2018b).

Así pues, se adopta en este artículo el novedoso enfoque construccionista para analizar el cambio de estilo en las cartas cortesanas del conde de Tendilla, con la intención de profundizar en los cambios lingüísticos que se estaban produciendo en la sociedad y que fueron captados por los hablantes y aprovechados en su beneficio.

\section{OBjetivos}

Se describirán los distintos esquemas de tratamiento del Ep.Tendilla en función de los destinatarios de las cartas y del asunto tratado. Estos esquemas se conciben como opciones estilísticas que el conde maneja para ofrecer una determinada imagen de sí mismo y conseguir sus objetivos, unas veces políticos, relacionados con su papel de capitán general del reino de Granada, otras veces personales, vinculados con la gestión de su propio patrimonio e intereses privados. Se destacará la importancia de analizar la variación diafásica de un individuo particular, porque a través de los estilos, los hablantes adoptan diferentes posiciones sociales; además, la variación estilística interna (de un solo hablante) deriva y se hace eco de la variación que existe entre los hablantes en el seno de una determinada comunidad, por lo que es especialmente útil para identificar qué recursos lingüísticos son más susceptibles de alterarse en función de las características del destinatario. En concreto, se analizarán los siguientes aspectos del Ep.Tendilla:

1. Cuántos esquemas de trato diferentes pueden identificarse en las cartas escritas entre los años 1513 y 1515.

2. Qué factores extralingüísticos determinan la variación estilística en el tratamiento.

3. Qué variables lingüísticas son más relevantes dentro de los diferentes esquemas de trato para proyectar la identidad y el posicionamiento so- 
cial de D. Íñigo, tanto en su faceta personal como en su dimensión de hombre de estado.

4. En qué medida el estilo epistolar del conde reproduce los patrones de trato característicos de la sociedad de principios del s. XVI o se aparta de ellos.

5. Cómo se articulan en el estilo epistolar cortesano los tres paradigmas pronominales que estaban a disposición de los hablantes de la época: el tuteante, el voseante y el incipiente "vuestramercedeante", con concordancia novedosa en tercera persona.

\section{Corpus de ESTUdio: CLASIFICACiÓN DE LAS CARTAS}

El corpus de análisis está constituido por las 1357 cartas del Ep.Tendilla que dictó el conde (excluidas las 315 últimas, redactadas por su hijo Luis). Las misivas pueden clasificarse en función del tipo de destinatario (Moreno Trujillo 42-43) en cuatro grupos distintos:

a) Cartas dirigidas a subordinados de niveles bajos y medios, directamente relacionadas con el papel de capitán general del reino de Granada. Los destinatarios son capitanes, veedores, pagadores, artesanos, ${ }^{1}$ sometidos directamente a la jurisdicción de D. Íñigo, o miembros intermedios de la justicia, como los corregidores, con los que el conde mantiene complejas relaciones de poder, por depender directamente del rey.

b) Cartas dirigidas a los concejos municipales integrados en el reino de Granada, encargados de la administración y justicia locales.

c) Cartas dirigidas a su secretario personal Francisco Ortiz, que actúa de emisario de máxima confianza ante la corte y las distintas personalidades con las que mantenía contactos políticos, económicos y diplomáticos.

d) Cartas dirigidas a miembros de la nobleza o el alto clero: con algunos goza de absoluta confianza, como con su consuegro el licenciado Francisco de Vargas, tesorero general de los Reyes Católicos, o el alcaide de Málaga, Íñigo Manrique; con otros mantiene una relación

1. Carpinteros, albañiles y fundidores, a los que se dirige como "maese + nombre propio" (Maese Diego, Maese Pedro, etc.). 
distante, incluso mala, como ocurre con el Gran Capitán, el duque de Alba o el arzobispo de Granada, Antonio de Rojas. Mención aparte en este grupo, por contar con un tratamiento específico, merecen las cartas dirigidas al rey, al que trata de vuestra alteza, y las que envía a su hijo Luis, el único caso de tuteo registrado en el corpus. ${ }^{2}$

Esta clasificación ha sido muy útil para identificar los principales esquemas de tratamiento del Ep.Tendilla. En líneas generales, que se precisarán en el análisis detallado de los resultados (apartados 5 y 6 ), puede decirse que el factor social decisivo, desencadenante de dos esquemas radicalmente distintos, viene dado por la condición nobiliaria del destinatario: el estatus noble (grupo d, analizado en el apartado 6) se reconoce mediante el uso reiterativo de fórmulas indirectas (vuestra merced, vuestra señoría, vuestra alteza), que están ausentes en los destinatarios de los grupos a, b y c (apartado 5).

\section{Voseo Autoritario, DEFERENTE E ÍNTIMO EN EL EP.TENDILLA}

El conde emplea tres tipos de voseo con tres funciones comunicativas diferentes: dar órdenes tajantes (voseo autoritario), pedir amablemente (voseo deferente) y tratar asuntos confidenciales (voseo íntimo). Se ilustran los tres modelos, respectivamente, en las misivas dirigidas al capitán Luis de Paz (37 cartas, 4729 palabras), a los corregidores de Málaga (20 cartas, 5881 palabras) y a su secretario personal Francisco Ortiz (10 cartas, 9189 palabras).

\subsection{Voseo autoritario en las cartas al capitán Luis de Paz}

Son cartas muy directas y breves. En ellas D. Íñigo da órdenes relacionadas con la disposición o el movimiento de las tropas, la contratación y despido de soldados, el pago de atrasos, etc.

En el encabezamiento aparece directamente el título y el nombre del destinatario ("Capitán Luys de Paz", carta 159) o fórmulas más amables, del tipo "pariente, señor" (carta 140) o "pariente, señor y amigo" (carta 208). Seguidamente, se dan órdenes tajantes que requieren cumplimiento inmediato: abundan el imperativo y las perífrasis obligativas, acompañados del adverbio luego

2. "Muy amado hijo: Luego como esta veas, haz sacar de los libros de los veedores o contadores toda la gente... Esto haz luego, y presenta tú mismo estas provisiones y cartas en el cabildo" (carta 760$)$. 
y otras fórmulas de apremio: "luego como esta veáys os venid aquí... y esto se haga syn dilaçión ninguna" (carta 9), "como esta veáys, menbiad aquí a todos los escuderos" (carta 407), "a Chincilla avisad que... no a de yrse a Málaga" (carta 601), "y esto se haga con mucha diligencia” (carta 411).

$\mathrm{El}$ paradigma es siempre voseante, con el pronombre vos como sujeto y término de preposición, sin aditamentos nominales: "vos le darés la gente que para todo fuere menester" (carta 316), "en lugar de la lança quél a vos os ha de enbiar" (carta 140).

Las despedidas son también muy austeras: una simple fecha ("fecho a XX de enero DXIII años" (carta 159), un escueto "vuestro" (carta 2), "quedo muy vuestro" (carta 411), o la forma rutinaria "Y nuestro señor y etc." (carta 9), equivalente a "Y nuestro señor (v)os guarde" o "(v)os aya en su guarda".

\subsection{Voseo deferente en las cartas a los corregidores de Málaga}

Las cartas enviadas a los corregidores son especialmente interesantes porque en ellas el conde tiene que poner en funcionamiento todas sus dotes diplomáticas. Aunque era capitán general del reino, su capacidad de maniobra estaba limitada por el poder de los corregidores, representantes del rey y encargados de administrar justicia en su nombre. Por consiguiente, cualquier intromisión inadecuada podría interpretarse como un desacato a la autoridad regia, algo que Tendilla temía por encima de todo.

Entre 1513 y 1515 mantiene correspondencia con dos corregidores de Málaga: primero con Garci Tello y desde junio de 1514 con Hernando de Vega. A ambos los trata de vos, con paradigma etimológico de segunda persona de plural, pero con el refuerzo nominal señor empleado de forma reiterada. ${ }^{3} \mathrm{El}$ vocativo sirve de recurso atenuador para reducir la agresión de actos de habla en los que se ordena o pide, o se contradice al interlocutor (Calderón Campos 2019b, 92-93).

En primer lugar, se utiliza señor para contradecir opiniones respetuosamente. Así ocurre en un problema de jurisdicciones entre la corregiduría y la villa de Vélez. El corregidor se queja de que el alcalde y el alguacil lleven vara de justicia, en menoscabo de la autoridad real. La opinión contraria de Tendilla se atenúa con el vocativo señor al principio de la argumentación:

3. Para usos de señor en la literatura clásica, ver Iglesias Recuero, en este mismo volumen; para señora, ver García-Godoy y Kluge, también en este volumen. 
(1) Dezís, señor, que reçibe agravio vuestra juridiçión en que trayan vara ell alcalde y el alguazil de la guarniçión de Bélez, yo no entiendo ell agravio por dos cosas... (carta 81)

En segundo lugar, es constante la presencia de señor cada vez que el conde expresa una petición que considera controvertida. En septiembre de 1514 se había recibido orden real para obligar a los moriscos a vivir a más de tres leguas de la costa, con objeto de evitar su huida o colaboración con los ataques norteafricanos. Esto perjudica los intereses de D. Íñigo en su villa de Almayate, por lo que intenta convencer al corregidor de que permita a los "nuevamente convertidos" (en contra de la cédula real) permanecer cerca de la costa mientras recogen los higos y uvas. La petición es extremadamente delicada, porque entran en conflicto los intereses económicos del conde con las órdenes del rey. Tendilla empieza dejando claro que no ha actuado por su cuenta y reafirmando, mediante el vocativo señor, la autoridad del corregidor: "no quise dispensar en cosa ninguna syn que vos, señor, viésedes y hiziésedes en esto lo que os paresçiese" (carta 638). Inmediatamente después añade la petición, ya atenuada con los preliminares deferentes: "pidos por merçed que mientra cojen los frutos... dispenséys con ellos" (carta 638).

Señor, por último, acompaña a cualquier enunciado cortés, como elemento deferente y adulador por excelencia, como cuando Tendilla da la bienvenida al recién nombrado corregidor: "Gran plaser he avido que persona no solo tan virtuosa como vos, señor, soys, mas tan experimentado... sea venido a este cargo" (carta 433).

El vocativo se presenta, por tanto, como el elemento diferenciador de las dos estrategias comunicativas del conde hacia sus subordinados del grupo a): ${ }^{4}$ en las cartas imperativas a Luis de Paz solo está presente en la fórmula de saludo del encabezamiento ("pariente señor" o "señor pariente"), y totalmente ausente en el cuerpo de la epístola; por el contrario, en las veinte cartas a los corregidores, donde el conde tiene que mostrarse diplomático y conciliador, sigue usándose en los encabezamientos ("Noble señor primo", "señor pariente",, 5 "Muy virtuoso señor" $)$, pero sobre todo se intercala en el cuerpo de la carta, donde se emplea hasta en 50 ocasiones, como atenuador cortés.

\footnotetext{
4. Por otra parte, a los corregidores no les da órdenes, sino que les "pide por merced": en total, la expresión se repite en dieciséis ocasiones ("Pidos por merçed hagáys saber cómo va", carta 591), en seis de las cuales se refuerza con señor ("Sea creydo, pídoslo, señor, por merçed", carta 591).

5. En las 4 cartas que dirige a Garci Tello.

6. En las 16 cartas enviadas a Hernando de Vega.
} 
En estas mismas cartas, el pronombre vos aparece 31 veces. Es muy significativa la colocación de señor justo detrás de vos (15 casos): "que no creyesen en la corte que era contra mí lo que vos, señor, escreuíades" (carta 1147), o en su entorno próximo (5 casos): "quise, señor, escreuiros a vos el agravio que reçebía" (carta 1147). Es decir, señor refuerza a vos en el $65 \%$ de los casos en que este pronombre se hace explícito (en 20 de 31 ejemplos de vos).

En resumen, el conde de Tendilla se vale de dos recursos para gestionar su relación con los miembros del grupo a): usa el vos escueto para dar órdenes de cumplimiento inmediato y para reforzar su imagen de autoridad suprema e indiscutible; y la fórmula vos + señor como estrategia general de cortesía.

\subsection{Voseo intimo en las cartas a Francisco Ortiz}

Francisco Ortiz es el secretario personal de Tendilla y el mediador de todos sus asuntos en la corte. A él le escribe las cartas más extensas y francas del epistolario, con detalles y opiniones críticas sobre los personajes de la vida política granadina:

(2) $\mathrm{El}$ arçobispo de Granada era tenido aquí por onbre baxo y ratero... y este su provisor es vn gran neçio y synple (carta 649)

(3) Que nos dieron aquí vn pesquisidor neçio y gordo y baxo y menguado de manos, que pareçe çepa podada (carta 566)

Con Ortiz tiene una relación de máxima confianza. Las misivas sirven para organizar la estrategia que debe seguir para defender los intereses del conde. Son, por tanto, cartas de negocios, pero en ellas los asuntos oficiales son tratados con total espontaneidad, por lo que revelan las convenciones del trato íntimo entre dos amigos de principios del siglo XVI, sin estereotipos ni ceremoniales cortesanos.

Tendilla cuenta libremente lo que ocurre en el reino de Granada o en su vida personal, para que el secretario actúe con conocimiento de causa. Le da instrucciones, le advierte de posibles amenazas y tretas contra sus intereses y diseña la estrategia que debe seguir en la negociación con los amigos y enemigos de la corte. Son las cartas que mejor reflejan el registro coloquial del epistolario.

El encabezamiento es siempre el mismo: "Especial amigo"; y el trato voseante, sin necesidad de refuerzos nominales. D. Íñigo entra directamente en el tema, sin formulismos ni rodeos: "Por esta carta de Sedano verés cómo en Adra 
no tyene gente ninguna... Mostrágela al rey secretamente, hablalde y dezilde que..." (carta 154); "Vos, por mi parte, no hablés palabra en esto más... Procurá, si podés... que Juan Ribera pueda entrar en la Alpuxarra...” (194). La despedida es también escasamente protocolaria: "Dios os aya en su guarda", "Y Dios os guarde".

En conclusión, los tres tipos de voseo del epistolario indican cambios de estilo del conde que le permiten ofrecer tres imágenes distintas de sí mismo: la de capitán general omnipotente (cartas a Luis de Paz), la de capitán general cauteloso con la autoridad real (cartas a los corregidores) y la de amigo íntimo (cartas a su secretario). Pero al mismo tiempo, las cartas ponen de manifiesto el valor que el voseo tenía en la sociedad de principios del XVI: sin aditamentos nominales, vos implicaba superioridad manifiesta respecto del destinatario (Luis de Paz) o intimidad (Francisco Ortiz); solo reforzado con el vocativo senor conservaba su valor deferente medieval. Lo verdaderamente significativo es que el trato voseante había perdido la antigua capacidad de reconocer el estatus nobiliario del interlocutor, reconocimiento que en el epistolario se hace únicamente por medio de las fórmulas indirectas (apartado 6).

\subsection{Cartas a los concejos municipales: el uso de vosotros en el epistolario}

Las cartas a los concejos municipales comparten muchos de los rasgos de las enviadas a los capitanes y corregidores, con la única diferencia de que ahora el conde escribe a varios destinatarios, sujetos también a su jurisdicción. En ellas se emplea siempre el paradigma de segunda persona de plural, con vacilación entre vos y vosotros. La forma arcaizante vos con valor de plural se mantiene en los usos formulísticos: "Hago saber a vos, los conçejos, alguaziles, vyejos y xóbenes..." (carta 191), "mando a todos e a cada vno de vos..." (carta 369). En los usos coloquiales se emplea vosotros: "que sy ay culpados entre vosotros que salgan de enmedio" (carta 1214), "e estado muy maravillado de vosotros... aver puesto tan poca diligençia...” (carta 1607).

En estas misivas, los usos lingüísticos del conde se acomodan a su intención: cuando da órdenes tajantes es directo, incluso amenazador:

(4) Yo os mando que luego saqués de las dichas casas los huéspedes que en ella están, so pena de $\mathrm{Xx}[\mathrm{M}]$ maravedís (carta 278)

(5) Sabido he que ponés nigligençia en enbiar los peones... No se haga asy de aquí adelante, sy no, a los quel alguazil... señalaré vayan a la dicha lavor (carta 487) 
Si las circunstancias lo permiten, se muestra amable (ejemplo 6) y agradecido, recurriendo ocasionalmente al vocativo cortés señores para disculparse (ejemplo 7) o pedir favores (ejemplo 8):

(6) Reçeví vuestra carta y no es menester que me dedes graçias ninguna por cosa que yo haga por vosotros... que os tengo a todos amor como a debdos çercanos (carta 911)

(7) Quanto a lo que dezís, señores, que toman prendas a pastores... digo que... a mí me pesa mucho dello y no creáys que de mi plaser ni voluntad proçede que los míos hagan ningund desacatamiento (carta 929)

(8) Pidos, señores, por merçed mandéys aposentar en esa çibdad a mí y a los que conmigo van (carta 1511)

En resumen, las cartas a los concejos se caracterizan por el empleo sistemático del paradigma de vosotros, con escasos aditamentos nominales corteses, en consonancia con el papel de capitán general del reino, que es el que el conde asume ante las corporaciones municipales, a las que, normalmente, da instrucciones sobre el orden y "guarda" del territorio.

\section{TRATAMIENTOS INDIRECTOS EN EL EPISTOLARIO: VUESTRA MERCED, VUESTRA SEÑORÍA Y VUESTRA ALTEZA}

En este apartado se ofrecen los resultados del análisis de las cartas enviadas a miembros de la nobleza o el alto clero (grupo d), cuyo estatus se reconoce por medio de tratamientos indirectos (García-Godoy 238-55), representados en el Ep.Tendilla por los sintagmas nominales vuestra merced, vuestra señoría y vuestra alteza. Este prestigioso uso innovador, que se empezó a propagar con fuerza en la corte castellana en el siglo XV (Tuten 2190), revolucionó la historia de los tratamientos. La principal innovación consistía en mostrar deferencia mediante grupos nominales inductores de concordancias en tercera persona ("a vuestra merced le suplico que responda a esta carta"), en lugar de emplear, como se había hecho durante toda la Edad Media, el pronombre vos acompañado de segunda persona de plural (“a vos, señor, os suplico que respondáis a esta carta”).

Las nuevas fórmulas son intrínsecamente ambivalentes, puesto que desde el punto de vista sintáctico inducen concordancias en tercera persona, pero desde el punto de vista semántico favorecen las de segunda ("a vuestra merced os suplico que respondáis a esta carta”). El epistolario está plagado de ejemplos en los que el conde utiliza una u otra concordancia, de manera aparentemen- 
te aleatoria. Obsérvese que en los ejemplos 9-11, el paradigma es exclusivo de tercera persona, pero en 12-18 alternan el de segunda y tercera:

(9) Sé que oyendo esto vuestra merçed lo hará mejor... (carta 700)

(10) Suplico a vuestra merçed diga y suplique al rey (carta 799)

(11) Besan las manos a vuestra merçed y quedo $s u$ seruidor (carta 39)

(12) Reçebí una carta de vuestra merçed en que me hazés saber... (carta 655)

(13) Ya sabe vuestra merçed cómo me mandastes por una carta que... (carta 700 )

(14) Suplico a vuestra merçed sea creydo y quedo a vuestro seruiçio (carta 105$)$

(15) Trabaje vuestra merçed que le oyan y vos, señor, creeldo (carta 109)

(16) Con él, señor, os suplico me mande vuestra merçed haser saber de su salud (carta 27)

(17) Las manos os beso por la merçed que vuestra señoría me bizo... (carta 1283)

(18) Dizen que vuestro llamamiento es para eso. Suplico a vuestra señoría de todo me avise (carta 1159)

En las líneas que siguen se analizará el uso que hace D. Íñigo de las fórmulas indirectas, para demostrar que su distribución y frecuencia no es arbitraria, sino que responde a unos patrones directamente relacionados con la estrategia comunicativa del conde.

\subsection{Teorías sobre la supleción paradigmática}

Se denomina supleción a la "sustitución de una base por otra de igual significado en determinadas formas de un paradigma" (DLE, s.v. supleción). Ejemplos como los de 12-18 constituyen muestras del paradigma supletivo (García 1822) formado por vuestra merced (o vuestra señoría) y vos a principios del siglo XVI.

Los historiadores de la lengua han abordado la supleción desde distintas ópticas, aludiendo primeramente a una "mezcla indiscriminada" de vos y vuestra merced (Castillo Mathieu 609), en la que las fórmulas nominales indirectas se comportan como "bloques erráticos", lo que provoca "constantes rupturas y transiciones entre secuencias concebidas en la tercera persona [...] y otras que mantienen el voseo de base" (Eberenz 110). Las fórmulas del tipo vuestra merced se perciben como unidades todavía "mal integradas" (Eberenz 113) o "injertadas" (Koch 78) en un sistema binario basado en la oposición medieval entre tú y vos. 
Se ha hablado también de mezcla de paradigmas (Fontanella de Weinberg 20;7 Calderón Campos 2003, 7) y de la "lenta creación de un paradigma propio" en el que los anafóricos le y su tuvieron que "adquirir referencia deíctica" (Iglesias Recuero 1883), o se ha tratado el problema desde la teoría de la gramaticalización, en la que la supleción podría interpretarse como un uso de vuestra merced más próximo al de un sintagma nominal que al de un pronombre (Bertolotti 105).

Recientemente, Lara Bermejo ha analizado la supleción de ustedes y vosotros en el occidente de Andalucía ("ustedes no os disteis cuenta", "ustedes no se disteis cuenta", "ustedes no se dieron cuenta"), fenómeno relacionado con la irrupción de vuestra merced en el paradigma voseante del siglo XV, dado que la extensión de la concordancia sintáctica no se produce al azar, sino que sigue un comportamiento gradual y jerárquico. El pronombre sujeto ustedes atrae primeramente al reflexivo y al verbo ("ustedes se acuerdan"). Progresivamen-

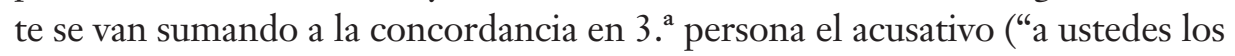
vi pasear") y el dativo ("a ustedes les doy un abrazo"). El posesivo es el último en adoptar la concordancia sintáctica y el más reacio a hacerlo (2018a, 100).

Por último, la supleción de vuestra merced y vos en el $\mathrm{s}$. XV y principios del XVI ha sido tratada por Erica C. García (18-22). Por medio de un análisis cuantitativo de correspondencia de la época, demuestra que la variación entre vuestra merced (o vuestra señoría) y vos no es arbitraria, sino que se explica como resultado de una especialización paradigmática según la cual las formas afines a vuestra merced predominan en las posiciones término de preposición ("escribiré a vuestra merced", carta 584) y sujeto explícito ("Ya sabe vuestra merced", carta 594), mientras que las formas del paradigma voseante se prefieren en el clítico ("no crea vuestra merced que os quitaré nada", carta 584) y el posesivo ("escriva vuestra merced a Antón García que cobra por vuestro mandado", carta 242).

Esta constatación estadística le hace formular una hipótesis según la cual cuando se utiliza un paradigma supletivo predominan como sujeto y término del sintagma preposicional aquellos elementos que gozan de mayor valoración sociolingüística, y como clíticos y posesivos aquellos que facilitan la identificación más clara y rápida del alocutario o favorecen una interpretación de mayor cercanía hacia el interlocutor. Es decir, los hablantes escogen para las po-

7. En el caso de Fontanella, la mezcla de paradigmas se refiere al voseo, donde la fusión tiene lugar entre vos y tú ("a vos te digo"). 
siciones que mayor probabilidad tienen de llamar la atención del destinatario (sujeto y término del grupo preposicional), las formas más valoradas socialmente; y colocan en las posiciones menos perceptibles (clítico, posesivo) las formas menos ambiguas respecto de la identificación del interlocutor y que se interpretan más fácilmente como cercanas y amistosas.

Parece evidente que vuestra merced y vuestra señoría, que habían surgido en ambientes nobiliarios cortesanos, gozaban a principios del siglo XVI de mayor valoración que el tradicional vos, lo que permite suponer la preferencia de aquellas formas como nominativo y término de preposición.

Por otra parte, para dirigirse a un destinatario resultaba menos ambiguo os, que venía empleándose durante toda la Edad Media con valor de segunda persona singular, que $l e$, cuyo uso hasta entonces era puramente anafórico, desvinculado de la segunda persona. Y lo mismo cabe decir de vuestro, respecto de su, suyo. De esta forma, "os suplico" y "beso vuestras manos" requerirían un menor esfuerzo interpretativo que "le suplico" o "beso sus manos".

Por último, la afectividad se vincula mucho más fácilmente con la segunda persona que con la tercera, por lo que resultarían más cordiales expresiones como "que Dios vuestra casa acreciente", o "Dios os guarde", que sus rivales en tercera persona "que Dios su casa acreciente", "Dios le guarde".

En conclusión, podría formularse una gradación como la indicada abajo, en la que a medida que nos aproximamos al extremo izquierdo, representado por el paradigma tuteante, se incrementan los valores + directo, + cercano y - ambiguo, valores que van decreciendo a medida que nos desplazamos hacia la esfera de la tercera persona, donde aumentan el tono cortés y reverencial (ver Lara Bermejo 2018b, 18):

$$
\begin{gathered}
\text { te }>\text { os }>\text { le } \\
\text { tu, tuyo }>\text { vuestro }>\text { su, suyo } \\
\text { 2. } .^{\text {a }} \text { persona sg. }>2 .^{\text {a }} \text { persona pl. }>3 .^{\text {a }} \text { persona sg. }
\end{gathered}
$$

\subsection{El paradigma supletivo en el epistolario: vuestra merced}

Para comprobar la hipótesis de García, reformulada en el apartado anterior, se han elaborado tres subcorpus: el primero está compuesto por 61 cartas (16 052 palabras) en las que el conde trata a sus interlocutores de vuestra merced; el segundo lo constituyen otras 61 cartas (15 990 palabras) con tratamiento de vuestra señoría; por último, el tercero está formado por todas las cartas dirigidas al rey (46 cartas, 13015 palabras), al que se trata de vuestra alteza. 
En los tres corpus se han contabilizado, por un lado, el número de elementos del paradigma de tercera persona, vinculados a vuestra merced (corpus 1), vuestra señoría (corpus 2) o vuestra alteza (corpus 3), y por otro, el de elementos voseantes, clasificándolos en las cinco posiciones que se analizan en el trabajo de García (18): sujeto explícito, término del sintagma preposicional, clítico, ${ }^{8}$ posesivo y terminación verbal. El resultado se muestra en la tabla 1:

\begin{tabular}{|c|c|c|c|c|c|c|c|c|c|c|}
\hline \multirow[b]{2}{*}{ Corpus 1} & \multicolumn{2}{|c|}{ SUJETO } & \multicolumn{2}{|c|}{ SPREP. } & \multicolumn{2}{|c|}{ CLítico } & \multicolumn{2}{|c|}{ POSESIVO } & \multicolumn{2}{|c|}{ VERBO } \\
\hline & VM & VOS & prep + vM & prep + vos & $3 s g$. & $2 \mathrm{pl}$. & su & vuestro & $3 s g$. & $2 \mathrm{pl}$. \\
\hline & 85 & 11 & 100 & 6 & 15 & 58 & 36 & 53 & 111 & 84 \\
\hline & $89 \%$ & $11 \%$ & $94 \%$ & $6 \%$ & $21 \%$ & $79 \%$ & $40 \%$ & $60 \%$ & $57 \%$ & $43 \%$ \\
\hline \multirow[t]{3}{*}{ Corpus 2} & vs & vOS & prep + vs & prep + vos & $3 s g$. & $2 \mathrm{pl}$. & su & vuestro & $3 s g$. & $2 \mathrm{pl}$. \\
\hline & 99 & 3 & 174 & 9 & 43 & 19 & 56 & 20 & 186 & 34 \\
\hline & $97 \%$ & $3 \%$ & $95 \%$ & $5 \%$ & $69 \%$ & $31 \%$ & $74 \%$ & $26 \%$ & $85 \%$ & $15 \%$ \\
\hline \multirow[t]{3}{*}{ Corpus 3} & VA & VOS & prep + VA & prep + vos & $3 s g$. & $2 \mathrm{pl}$. & su & vuestro & $3 s g$. & $2 \mathrm{pl}$. \\
\hline & 91 & 0 & 161 & 0 & 15 & 1 & 44 & 3 & 160 & 0 \\
\hline & $100 \%$ & $0 \%$ & $100 \%$ & $0 \%$ & $94 \%$ & $6 \%$ & $94 \%$ & $6 \%$ & $100 \%$ & $0 \%$ \\
\hline
\end{tabular}

Tabla 1. Frecuencia de uso de formas de $3 .^{\mathrm{a}} \mathrm{sg} . \mathrm{y} 2 .^{\mathrm{a}} \mathrm{pl}$. con tratamientos indirectos.

En el corpus 1, Tendilla emplea un paradigma claramente supletivo. Como término del sintagma preposicional y sujeto es predominante el empleo de vuestra merced (en el $94 \%$ y $89 \%$ de los casos, respectivamente). Por el contrario, el paradigma voseante es mayoritario en el clítico (79\%), donde se prefiere os a le, ge o se, y el posesivo (60\%), con preferencia de vuestro respecto de su о suyo.

En la terminación verbal es donde se aprecia menos diferencia entre la 2. ${ }^{\mathrm{a}}$ y la $3 .{ }^{\mathrm{a}}$ persona, a favor de esta última (57 \%). Sin lugar a dudas, el factor decisivo que determina la desinencia verbal es la presencia de vuestra merced, como sujeto explícito inductor de la concordancia, y la cercanía del elemento

8. García no hace distinción en las funciones que puedan desempeñar el grupo prepositivo ni el clítico. Esta distinción, que no se hace en la tabla 1, será analizada en 6.4. 
que la recibe, en este caso el verbo (Corbett): en un entorno de cinco palabras a la izquierda y cinco a la derecha, vuestra merced atrae formas verbales de $3 .^{a}$ persona en 71 ocasiones; $^{9}$ en el mismo entorno, solo aparecen seis casos de desinencias de $2 .{ }^{a}$ de plural. ${ }^{10}$ Cuando vuestra merced no está presente en el entorno próximo, las formas verbales pueden adoptar desinencias de segunda persona ("hagáys", ej. 19):

(19) En esta no diremos [más] de besaros las manos por lo que vuestra merçed dize en la carta que Ortyz me truxo, y para comienço de pago os suplico, señor, que me hagáys merçed de suplicar a su alteza... (carta 62)

En 20 se muestra un ejemplo prototípico del paradigma supletivo del corpus 1:

(20) Suplícoos, señor, que vuestra merced lo diga a su alteza... Que nuestro señor guarde a vuestra merced de los malos ombres... A vuestro servicio señor (carta 542)

Con este juego supletivo, Tendilla aplica una estrategia comunicativa de especialización paradigmática: recurre a vuestra merced para reconocer el estatus nobiliario del interlocutor, dado que el pronombre vos ya no realizaba esta función a principios del XVI (Tuten 2192); pero al mismo tiempo acude a elementos voseantes (os y vuestro) para mostrar un tono cordial y cercano con el destinatario, en consonancia con el uso característico del voseo íntimo (ver 5.3. y Fontanella de Weinberg 24), y para evitar la posible ambigüedad referencial de su y le (García 20).

Estas dos funciones (afectividad y menor ambigüedad) de la segunda persona se muestran de forma evidente en el ejemplo 21, tomado de una carta al licenciado Francisco de Vargas. El licenciado era tesorero general y consejero de Fernando el Católico, por lo que merecía tratamiento de merced, pero al mismo tiempo era consuegro de Tendilla, ${ }^{11}$ lo que implicaba cierto grado de confianza.

9. 47 casos de subjuntivo ("mande”, "tome”, “quiera”, "dé”, “diga”, “crea”, etc.), 12 de presente de indicativo ("tiene", "vee", "sabe", "haze", etc.), 9 de futuro ("podrá", "hará", etc.), 2 de pretérito perfecto simple ("escrivió", "hizo").

10. Son ejemplos como "Suplico a vuestra merçed mirés mucho por la señora" (carta 939), muy poco frecuentes.

11. El hijo del conde, Antonio de Mendoza, estaba casado con la hija del tesorero, Catalina de Vargas. 
(21) Esto os suplico, señor, diga vuestra merçed a su alteza, en respuesta de vuestra carta en que mescrevistes que su alteza mandava que en aquello se pusiese recaudo... A la señora mi hermana beso las manos y en merçed de la señora mi hija me encomiendo y vuestro hijo os besa las manos y juro por su vida y de sus hermanos que no es por mi voluntad su estada aquí (carta 377)

En el fragmento, Tendilla pone en acción su estrategia de especialización paradigmática: reconoce el estatus nobiliario del licenciado ("diga vuestra merçed") pero emplea formas del paradigma de segunda persona ("os suplico", "de vuestra carta" y "escrevistes") para evitar la posible ambigüedad de "le suplico" y, sobre todo, "de su carta" y "escribió", que podrían hacer referencia al rey.

Por último, en la despedida cordial, D. Íñigo tiene palabras cariñosas para su consuegra Inés de Carvajal ("mi hermana"), para su nuera ("mi hija") y para el propio tesorero: "vuestro hijo os besa las manos", es decir, Antonio de Mendoza, el hijo de Tendilla y yerno de Vargas le manda saludos a este y se disculpa por estar en Granada, apartado de su esposa. Obsérvese que vuestro y os aparecen en un contexto de clara intimidad, al tiempo que aluden inequívocamente al destinatario de la carta, Francisco de Vargas. El valor deíctico, directo y afectivo de vuestro y os contrasta con el anafórico de $s u(s)$ en "juro por su vida y de sus hermanos" [de Antonio de Mendoza].

\subsection{Hacia la nivelación en tercera persona: vuestra señoría y vuestra alteza}

El corpus 2 está compuesto por cartas dirigidas a miembros de la alta nobleza y del alto clero, a los que D. Íñigo trata de vuestra señoría. Si se analiza el gráfico 1, podrá apreciarse el incremento de la tercera persona en todas las posiciones, de manera muy significativa en la terminación verbal (85\%), aunque también en el posesivo (74 \%) y el clítico (69\%).

El ejemplo 22 podría considerarse representativo de la extensión de la concordancia de tercera persona apreciable en este subcorpus. No obstante, Tendilla sigue recurriendo, aunque con menor frecuencia, al paradigma supletivo, en el que combina vuestra señoría con elementos de segunda persona. Es notable en las cartas personales, como cuando habla desenfadadamente con el obispo de Málaga sobre el casamiento de su segunda hija (ej. 23):

(22) Nunca cosa tanto deseé como ver a vuestra señoría y hablarle largamente... Entre tanto, dirá a vuestra señoría el alcayde todo lo que sé... vuestra señoría le conseje como a suyo (carta 431) 
(23) La otra, señor, muchacha es, mas daquí a un año puede ser; sy una vez me habló vuestra señoría vn casamiento y, ipor Dios!, señor, que entiendo era bueno, antes que vades de ay os yré a ver y hablaremos... Estas mis cartas non vea nadie, rómpala vuestra señoría (carta 957)

Otro hecho significativo del corpus 2 es el número de misivas en las que el tratamiento es enteramente de tercera persona, sin ningún caso de alternancia. ${ }^{12}$ En 36 cartas (de un total de 61, es decir el $59 \%$ ), el conde ha nivelado el paradigma. En el corpus 1 este porcentaje se reduce al $21 \%$ (13 cartas de 61), lo que equivale a decir que con vuestra merced, el paradigma es supletivo casi en el $80 \%$ de los casos, mientras que con vuestra señoría el porcentaje disminuye a la mitad (41\%).

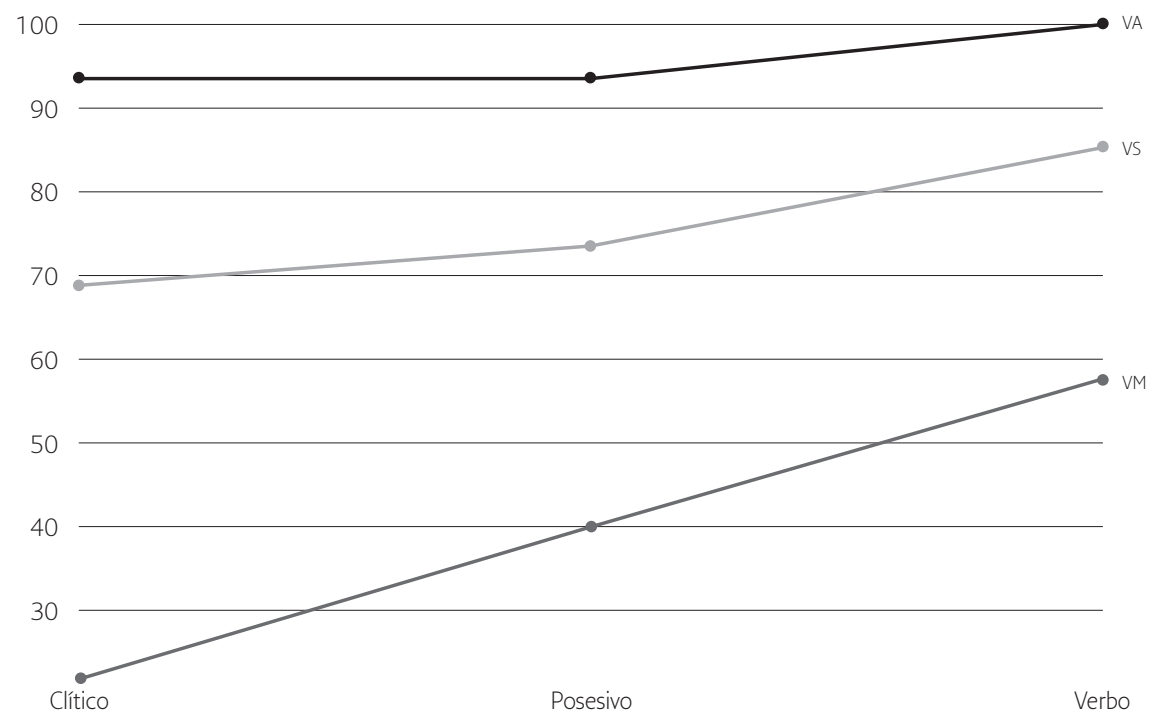

Gráfico 1. Porcentaje de la concordancia de tercera persona con vuestra merced, vuestra señoría y vuestra alteza.

Por último, en el corpus 3, compuesto por cartas dirigidas al rey, el supletivismo prácticamente ha desaparecido a favor de un paradigma nivelado en tercera persona, en concordancia con vuestra alteza. Ahora el $93 \%$ de las cartas se redactan íntegramente con concordancia sintáctica, como en 24:

12. Significativamente, en cartas escritas a personajes con los que el conde mantenía una relación distante, como el Gran Capitán. 
(24) Beso las reales manos de vuestra alteza y le hago saber como reçebí vna çédula de vuestra alteza en que me manda que enbie a vuestra alteza mi voto y pareçer... De vuestra alteza humill syervo sus reales manos beso. El marqués, don Yñigo (carta 384) $)^{13}$

El avance de la tercera persona se aprecia claramente en el gráfico 1: vuestra merced genera un típico paradigma supletivo, con predominio de os y vuestro sobre sus rivales. Con vuestra señoría se impone la concordancia sintáctica en todas las posiciones, clítico y posesivo incluidos. Todavía la 2. ${ }^{\mathrm{a}}$ persona es apreciable ( $26 \%$ de vuestro, $31 \%$ de os), sobre todo cuando os y vuestro no están cerca del sintagma vuestra señoría o cuando el interlocutor forma parte de la esfera íntima del conde. En el caso de vuestra alteza, la concordancia se ha nivelado prácticamente, salvo en casos muy excepcionales.

\subsection{La expresión del dativo, de la posesión y del acusativo en las cartas a la nobleza}

En teoría, el conde tenía cuatro opciones para expresar el dativo, la posesión y el acusativo, que se representan, respectivamente, en a, b y c. Se trata, por un lado, de dos opciones de tercera persona ( 1 y 2 ), y dos de segunda (3 y 4), y por otro, de dos opciones preposicionales $(1$ y 4$)$ y dos no preposicionales (2 y 3).

a) Dativo
1) (Suplico) a vuestra + sustantivo
2) le (suplico)
3) os (suplico)
4) (Suplico) a vos

b) Posesión
1) (Una carta) de vuestra + sustantivo
2) (Una carta) suya
3) (Una carta) vuestra
4) (Una carta) de vos

13. El uso de la tercera persona para dirigirse al rey llega al extremo de que se registran casos de su alteza con valor alocutivo: "por esa carta de Luys de Paz verá su alteza lo que pudieron haser". En el resto del epistolario, las formas su merced y su señoría tienen siempre valor delocutivo: "Y pues la señora doña Ysabel, cuyas manos beso, syenpre lo acostunbra haser asy, a su merçed [es decir, «a ella»] lo suplico y quedo, señor, a vuestro seruiçio" (carta 939). 
c) Acusativo

1) (Ver) a vuestra + sustantivo

2) (Ver)lo

3) (Ver)os

4) (Ver) a vos

Sin embargo, el análisis estadístico de los corpus 1-3 indica que la elección de una u otra estructura no es aleatoria (ver tablas 2-4). Con vuestra merced, en casi la mitad de los casos para el dativo y el posesivo (47 \%, tabla 2; $42 \%$, tabla 3 ) se recurre a la segunda persona (os, vuestro), en consonancia con el carácter menos reverencial de vuestra merced respecto de las otras fórmulas nominales.

\begin{tabular}{c|c|c|c|c} 
& a vuestra + sust. & le & os & a vos \\
\hline $\begin{array}{c}\text { vM } \\
\text { Corpus 1 }\end{array}$ & $39 \%$ & $11 \%$ & $47 \%$ & $3 \%$ \\
\hline $\begin{array}{c}\text { vs } \\
\text { Corpus 2 }\end{array}$ & $58 \%$ & $26 \%$ & $12 \%$ & $4 \%$ \\
\hline $\begin{array}{c}\text { va } \\
\text { Corpus 3 }\end{array}$ & $84 \%$ & $15 \%$ & $1 \%$ & - \\
\hline
\end{tabular}

Tabla 2. Porcentaje de las distintas estructuras de dativo en cartas a la nobleza.

Por el contrario, si se suman las estructuras preposicionales y las no preposicionales, la concordancia de tercera persona es claramente mayoritaria cuando el tratamiento es vuestra señoría (84 \% para el dativo, tabla 2; $86 \%$ posesivo, tabla 3), o vuestra alteza (99 \% dativo, tabla 2; $98 \%$ posesivo, tabla 3). Para el acusativo la extensión de la tercera persona se da incluso con vuestra merced.

\begin{tabular}{c|c|c|c|c} 
& de vuestra + sust. & su, suyo & vuestro & de vos \\
\hline $\begin{array}{c}\text { VM } \\
\text { Corpus 1 }\end{array}$ & $30 \%$ & $28 \%$ & $42 \%$ & - \\
\hline $\begin{array}{c}\text { vs } \\
\text { Corpus 2 }\end{array}$ & $47 \%$ & $39 \%$ & $14 \%$ & - \\
\hline $\begin{array}{c}\text { VA } \\
\text { Corpus 3 }\end{array}$ & $61 \%$ & $37 \%$ & $2 \%$ & - \\
\hline
\end{tabular}

Tabla 3. Porcentaje de las distintas estructuras de posesivo en cartas a la nobleza. 
Por último, es muy destacable el alto porcentaje de estructuras preposicionales de tercera persona en todas las funciones, ${ }^{14} \sin$ duda porque presentan dos ventajas respecto de las otras: expresan cortesía y reverencia por medio del sustantivo, y evitan la ambigüedad de la opción no preposicional de tercera persona.

\begin{tabular}{c|c|c|c} 
& a vuestra + sust. & lo & os \\
\hline $\begin{array}{c}\text { VM } \\
\text { Corpus 1 }\end{array}$ & $75 \%$ & $5 \%$ & $20 \%$ \\
\hline $\begin{array}{c}\text { vs } \\
\text { Corpus 2 }\end{array}$ & $76 \%$ & $18 \%$ & $6 \%$ \\
\hline
\end{tabular}

Tabla 4. Porcentaje de las distintas estructuras de acusativo en cartas a la nobleza.

\section{CONCLUSIÓN}

El conde de Tendilla modifica sus esquemas de tratamiento en función del nivel social del destinatario (noble/plebeyo) y del tono afectivo de la misiva, en un juego muy sutil de plasmación de intenciones y de imagen personal, en el que hay que tener en cuenta las siguientes consideraciones:

a) La clave principal del sistema está en la oposición entre tratamientos directos (vos) e indirectos (vuestra merced, vuestra señoría y vuestra alte$z a)$, que se basa en un contraste de la segunda persona de plural, más directa y cercana, con la tercera de singular, más protocolaria y distante.

b) El voseo implica en el Ep.Tendilla superioridad jerárquica (voseo autoritario) o confianza (voseo íntimo).

c) Para reconocer el estatus nobiliario del interlocutor es necesario emplear reiteradamente tratamientos indirectos en las posiciones sujeto y término de la preposición, lo que provoca la sobrecarga de estructuras preposicionales (“a/de vuestra señoría”) en las funciones dativo, acusativo y posesivo.

d) Los tratamientos indirectos pueden concordar semánticamente con formas de segunda persona de plural, generando esquemas supletivos

14. De media, es la opción preferida en el $60 \%$ de los casos. 
regulados por una suerte de especialización paradigmática: en las posiciones indicadas en c) predominan los elementos que revelan la valoración social del conde; el clítico y el posesivo no preposicional sirven para marcar el tono afectivo de la misiva: os y vuestro implican mayor cercanía (y menor ambigüedad) que le y $s u$.

e) La expansión de la concordancia sintáctica en tercera persona se vincula con un rango social más elevado del destinatario (vuestra alteza > vuestra señoría > vuestra merced) o con un tono más distante y reverencial de la misiva.

f) El principal recurso para expresar atenuación y deferencia en todo el Ep.Tendilla es el vocativo señor, que puede combinarse tanto con vos como con los sintagmas nominales indirectos.

\section{OBRAS CITADAS}

Arias Álvarez, Beatriz, y Juan Antonio Hernández Mendoza. "Importancia de la incorporación de los parámetros diastráticos y diafásicos en la elaboración del corpus electrónico del español colonial mexicano". Scriptum Digital 2 (2013): 5-20.

Arrabal Rodríguez, Pilar. "Andalucismos léxicos en un corpus almeriense de inventarios". Vox Romanica 78 (2019): 243-65.

Auer, Anita. "Stylistic Variation". Letter Writing and Language Change. Eds. Anita Auer, Dani Schreier y Dick Watts. Cambridge: Cambridge UP, 2015. 133-55.

Bastardín Candón, Teresa. "Inventarios de bienes y lexicografía regional andaluza: a propósito de algunas voces documentadas en el AHPC". Retos y avances en lexicografía: los diccionarios de español en el eje de la variación linguiistica. Eds. Julia Sanmartín Sáez y Mercedes Quilis Merín. Valencia: Asociación Española de Estudios Lexicográficos, 2019. 113-30.

Bell, Allan. "Back in Style: Reworking Audience Design". Style and Sociolinguistic Variation. Eds. P. Eckert y John R. Rickford. Cambridge/New York: Cambridge UP, 2001. 139-69.

Bentivoglio, Paola. "Formas de tratamiento en cartas de la segunda mitad del siglo XVI: una aproximación pragmática". Archivo de filología aragonesa 5960.1 (2002-2004): 229-48.

Bertolotti, Virginia. "A mí de vos no me trata ni usted ni nadie": sistemas e historia de las formas de tratamiento en la lengua española en América. México: UNAM, 2015. 
Bravo-García, Eva. Las voces del contacto: edición y estudio de las Relaciones Geográficas de México (siglo XVI). Varsovia: Universidad de Varsovia, 2018.

Calderón Campos, Miguel. "Fórmulas de tratamiento en las cartas del conde de Tendilla (1504-1506)". Tonos digital: Revista de estudios filológicos 5 (2003): 1-11.

Calderón Campos, Miguel. "La edición de corpus históricos en la plataforma TEITOK: el caso de Oralia diacrónica del español (ODE)". CHIMERA: Romance Corpora and Linguistic Studies 6 (2019a): 21-36.

Calderón Campos, Miguel. " $A$ vuestras mercedes pido que veades esta carta: concordancia gramatical y concordancia pragmática en las cartas de estilo cortesano". Tendencias y perspectivas en el estudio de la morfosintaxis histórica bispanoamericana. Eds. Viorica Codita y Mariela de la Torre. Madrid: Iberoamericana/Frankfurt am Main: Vervuert, 2019b. 85-103.

Castillo Mathieu, Nicolás. "Testimonios del uso de vuestra merced, vos y tú en América (1500-1650)". Thesaurus: Boletín del Instituto Caro y Cuervo 37.3 (1982): 602-44.

Conde-Silvestre, Juan Camilo. "A Third-wave Historical Sociolinguistic Approach to Late Middle English Correspondence: Evidence from the Stonor Letters". Current Trends in Historical Sociolinguistics. Ed. Cinzia Russi. Varsovia/Berlín: Open De Gruyter, 2016. 46-66.

Corbett, Greville G. Agreement. Cambridge: Cambridge UP, 2006.

Coupland, Nikolas. "The Sociolinguistics of Style". The Cambridge Handbook of Sociolinguistics. Ed. Rajend Mesthrie. Cambridge: Cambridge UP, 2011. 138-56.

DLE: Real Academia Española. Diccionario de la lengua española. 23. ${ }^{a}$ ed. Madrid: Espasa, 2014.

Dossena, Marina, y Gabriella del Lungo Camiciotti, eds. Letter Writing in Late Modern Europe. Amsterdam/Philadelphia: John Benjamins, 2012.

Eberenz, Rolf. El español en el otoño de la Edad Media. Madrid: Gredos, 2000.

Eckert, Penny. Meaning and Linguistic Variation: The Third Wave in Sociolinguistics. Cambridge: Cambridge UP, 2018.

Fontanella de Weinberg, Beatriz. "La evolución de los usos americanos de segunda persona singular". Lingiuística 4 (1992): 7-25.

García, Erica C. "Una casilla vacía en el paradigma del voseo". El español de América en el siglo XVI (Actas del simposio del Instituto Iberoamericano de Berlin). Ed. Jens Lüdtke. Frankfurt am Main: Vervuert, 1994. 13-38. 
García-Godoy, María Teresa. "El tratamiento indirecto en el español colonial: los títulos honoríficos". Estudios de morfosintaxis histórica bispanoamericana, 1: El pronombre. Eds. Juan P. Sánchez Méndez, Antonio Corredor Aveledo y Elena Padrón Castilla. Valencia: Tirant Humanidades, 2019. 219-62. García-Mouton, Pilar. "Tratamientos en las cartas de Indias". Estudios de linguiistica hispánica: bomenaje a María Vaquero. Eds. Eduardo Forastieri, Julia Cardona, Humberto López Morales y Amparo Morales. San Juan: Editorial de la Universidad de Puerto Rico, 1999. 263-76.

Hernández-Campoy, Juan Manuel, y Juan Antonio Cutillas-Espinosa. "Speaker Design Practices in Political Discourse: A Case Study". Language and Communication 30 (2010): 297-309.

Hernández-Campoy, Juan Manuel, y Juan Antonio Cutillas-Espinosa, eds. Style-shifting in Public: New Perspectives on Stylistic Variation. Amsterdam/Philadelphia: John Benjamins, 2012.

Hernández-Campoy, Juan Manuel, y Tamara García-Vidal. "Style-shifting and Accomodative Competence in Late Middle English Written Correspondence: Putting Audience Design to the Test of Time". Folia Linguistica Historica 39.2 (2018a): 383-420.

Hernández-Campoy, Juan Manuel, y Tamara García-Vidal. "Persona Management and Identity Projection in English Medieval Society: Evidence from John Paston II". Fournal of Historical Sociolinguistics 4.1 (2018b): 33-63.

Iglesias Recuero, Silvia. "Aportaciones al origen de (la) vuestra merced como forma de tratamiento". Actas del VII Congreso Internacional de Historia de la Lengua Española. Eds. Concepción Company y José G. Moreno de Alba. Madrid: Arco Libros, 2008. 1869-84.

Koch, Peter. "Tradiciones discursivas y cambio lingüístico: el ejemplo del tratamiento vuestra merced en español". Sintaxis histórica del español y cambio lingüístico: nuevas perspectivas desde las tradiciones discursivas. Ed. Johannes Kabatek. Madrid: Iberoamericana, 2008. 53-88.

Lara Bermejo, Víctor. "Relaciones de caso y extensión de la concordancia en el español peninsular y el portugués europeo". Revista de Filología Española 98.1 (2018a): 85-110.

Lara Bermejo, Víctor. La cortesía en la Península Ibérica: dialectología del "Sprachbund" suroccidental. Berna: Peter Lang, 2018b.

Medina Morales, Francisca. "Los títulos de tratamiento en la España del siglo XVIII: la preceptiva de los tratados de cartas ilustrados". El español del siglo 
XVIII: cambios diacrónicos en el primer español moderno. Ed. María Teresa García-Godoy. Berna: Peter Lang, 2012. 195-218.

Morala, José R. "El CorLexIn, un corpus para el estudio del léxico histórico y dialectal del Siglo de Oro". Scriptum Digital 3 (2014): 5-28.

Morala, José R., y María Cristina Egido Fernández. "El proyecto CorLexIn y la variación diatópica en el léxico del Siglo de Oro". Historia del léxico español y Humanidades digitales. Eds. Dolores Corbella Díaz, Alejandro Fajardo Aguirre y Jutta Langenbacher-Liebgott. Berlín: Peter Lang, 2018. 397-418.

Moreno Trujillo, María Amparo. "La perfecta simbiosis de un humanista: la correspondencia del conde de Tendilla, entre la erudición y la cultura popular". Signo: revista de historia de la cultura escrita 8 (2001): 35-77.

Moreno Trujillo, María Amparo, Juan M. de la Obra Sierra y María José Osorio Pérez. Escribir y gobernar: el último registro de correspondencia del conde de Tendilla (1513-1515). Granada: Editorial Universidad de Granada, 2007.

Nurmi, Arja, Minna Nevala y Minna Palander-Collin, eds. The Language of Daily Life in England (1400-1800). Amsterdam/Philadelphia: John Benjamins, 2009.

Puche Lorenzo, Miguel Ángel. "Léxico dialectal/léxico especializado en los inventarios de bienes". Actas del x Congreso Internacional de Historia de la Lengua Española. Eds. María Luisa Arnal Purroy, Rosa María Castañer Martín, José María Enguita Utrilla, Vicente Lagüéns Gracia y María Antonia Martín Zorraquino. Zaragoza: Institución Fernando el Católico, 2018. 1655-70.

Sánchez-Prieto Borja, Pedro, y Delfina Vázquez Balonga. "Hacia un corpus de beneficencia en Madrid (siglos XVI-XIX)". Scriptum Digital 6 (2017): 83-103.

Stangl, Werner. "Un cuarto de siglo con Cartas privadas de inmigrantes a Indias: prácticas y perspectivas de ediciones de cartas transatlánticas en el Imperio español”. Anuario de estudios americanos 70.2 (2013): 703-36.

Toledo y Huerta, Álvaro Octavio de, y Lola Pons Rodríguez. Textos para la historia del español: queja política y escritura epistolar durante la Guerra de la Independencia: documentación de la funta Suprema Central en el AHN. Selección, edición y estudio lingüístico. Alcalá de Henares: UAH, 2017.

Torres Martínez, Marta. "Notas sobre el léxico documentado en cartas de dote almerienses del siglo XVIII". Historia del español, hoy: estudios y perspectivas. Ed. José Luis Ramírez Luengo. Lugo: Axac, 2014. 217-56. 
Torres Martínez, Marta. "Léxico de la vestimenta de expósitos giennenses (finales siglo XVIII)". Philologia Hispalensis 33.1 (2019): 147-60.

Tuten, Donald N. "Factores socioculturales en el desarrollo de vuestra merced/usted". Actas del VII Congreso Internacional de Historia de la Lengua Española. Eds. Concepción Company y José G. Moreno de Alba. Madrid: Arco Libros, 2008. 2189-200.

Vaamonde, Gael. "Escritura epistolar, edición digital y anotación de corpus". Cuadernos del Instituto Historia de la Lengua 11 (2018a): 139-64.

Vaamonde, Gael. "La multidisciplinariedad en la creación de corpus históricos: el caso de Post Scriptum”. Artnodes 22 (2018b): 118-27. 